\title{
Die rol van 'n plantkundige in Parke en Ontspanning
}

\author{
G.F. Smith \\ Departement Plantwetenskappe, Potchefstroomse Universiteit vir CHO, Potchefstroom 2520
}

Ontvang 26 Junie 1989; aanvaar 6 Desember 1989

\section{UITTREKSEL}

Die besonder ryk flora van Suidelike Afrika is internasionaal reeds sedert die vroeë sewentiende eeu bekend. Ons floristiese natuurerfenis is tans egter in 'n toenemende mate onderworpe aan druk voortspruitend uit industriële, stedelike en landboukundige ontwikkeling. Navorsing primer gerig op die bewaring van ons inheemse flora, die beskikbaarstelling van skaars, inheemse plantsoorte aan kwekerye en die vestiging van 'n lewensvatbare boomaanplantingsprogram kan egter deur Departemente van Parke en Ontspanning onderneem word. Opvoedkundige programme wat formele en nie-formele plantkundige onderrig insluit, kan ook daartoe bydra om die publiek bewus te maak van ons unieke flora. 'n Gegradueerde met plantkunde as een hoofvak kan binne Departemente van Parke en Ontspanning 'n belangrike bydrae lewer om natuurlike hulpbronne onder hulle beheer to bewaar en sinvol te benut.

\section{ABSTRACT}

\section{The role of a botanist in Parks and Recreation}

The exceptional wealth of the flora of Southern Africa has been known internationally since the early seventeenth century. However, our floral heritage has been subjected to ever increasing pressure resulting from industrial, urban and agricultural development. Research primarily aimed at conserving our indigenous flora, making rare species available to nurseries as well as establishing a meaningful tree planting programme can, however, be undertaken by Departments of Parks and Recreation. Educational programmes ranging from formal to non-formal botanical education can play an important role in making the public aware of our unique flora. A graduate presenting botany as one major subject can assist Departments of Parks and Recreation in utilizing these opportunities, not only to conserve, but also to develop the natural resources currently under their control.

\section{INLEIDING}

\subsection{Die unieke plantegroei van Suidelike Afrika}

Die besondere floristiese rykdom van Suidelike Afrika is reeds vir etlike eeue wêreldwyd bekend. ${ }^{1.2}$ Meer nog het die wetenskaplike ontleding van die unieke Kaapse tlora die verbeelding van plantkundiges tot so 'n mate aangegryp dat die sogenaamde Fynbosbioom as een van die ses floristiese ryke waarin die wêreld ingedeel is, erken word. ${ }^{3}$ Hierdie Kaapse floristiese ryk het aanvanklik $67000 \mathrm{~km}^{2}$ beslaan. Dit is onrusbarend dat slegs 42000 $\mathrm{km}^{2}$ of nagenoeg $63 \%$ hiervan nog nie deur menslike aktiwiteite beinvloed is nie. ${ }^{4}$ Vir hierdie streek is 8550 verskillende plantspesies reeds aangeteken, terwyl Wes-Australië, wat twintig keer groter is as die Kaapse ryk, oor slegs 7000 spesies beskik. ${ }^{4}$ Verder is op een plaas van 80 hektaar in die Klein Drakenstein 'n groter verskeidenheid Gladiolus-soorte versamel as wat in die hele Eurasië voorkom. ${ }^{5}$ Op die Kaapse Skiereiland kom meer as 2500 blomplantsoorte voor, wat meer is as die totale aantal spesies wat in Groot-Brittanje aangetref word. Van die 640 Erica-soorte wat wêreldwyd bekend is, kom 612 in SuidAfrika voor. ${ }^{6}$ Die Kaapse flora is nie alleen ryk aan spesies nie, maar beskik ook oor 'n groot hoeveelheid endemiese plantsoorte. 'n Opname wat 957 plantgenusse wat aan die Kaap voorkom, ingesluit het, het aangetoon dat 198 of $20,7 \%$ daarvan endemies is. ${ }^{7}$ Hierdie streek bevat egter ook $65 \%$ van die skaars en bedreigde plante van Suidelike Afrika. ${ }^{89}$

Dit is egter nie net die winterreënvalstreek van suidelike Afrika wat oor 'n groot verskeidenheid plantsoorte beskik nie. ${ }^{10}$ In Natal word meer as 4800 plantsoorte aangetref," in die Zuurberg Nasionale Park (Oos-Kaap) $1100^{12}$ en gesamentlik in suidelike Afrika net minder as $24000 .{ }^{13}$ Laasgenoemde getal is bykans dubbel die hoeveelheid plantsoorte wat in die hele Wes-Europa aangetref word en meer as die spesies wat onderskeidelik in die Verenigde State van Amerika en die Unie van Sosialistiese Sowjetrepublieke voorkom. ${ }^{14}$ Suidelike Afrika word hier gedefinieer as die landstreek suid van, maar uitsluitend, Angola, Zambië, Zimbabwe en Mosambiek.

Een van die redes waarom die Fynbosbioom so dikwels gebruik word ter illustrering van die agteruitgang van ons flora, is die groot hoeveelheid navorsing wat reeds daarop gedoen is. In ander streke van die land is inligting aangaande die bewaringstatus, spesiesamestelling en benuttingspotensiaal dikwels ontoereikend en fragmentaries. So, 
byvoorbeeld, is onlangs aangetoon hoe gebrekkig die inligting is wat oor die flora van die ryke Karoobioom beskikbaar is. ${ }^{15.16} \mathrm{Na}$ aanleiding van navorsing gedoen in die Valleibosveld $^{17}$ van die Oos-Kaap kon die ontoereikende bewaringstatus van hierdie veldtipe beklemtoon word ${ }^{18,19,20}$ Hieruit het geblyk dat slegs nagenoeg $1,2 \%$ van Valleibosveld tans enige vorm van bewaring geniet. Dit is egter noemenswaardig dat die Bronnereservaat, wat net buite Uitenhage geleë is en in hierdie veldtipe val, deur die Afdeling Parke en Ontspanning van Uitenhage bestuur word. Hierdie reservaat beslaan ongeveer 411 hektaar. Daar bestaan dus min twyfel oor die unieke floras wat ook in ander streke van die RSA aangetref word.

Werknemers van Parke en Ontspanning in 'n plaaslike owerheid lewer op hoofsaaklik drie terreine 'n bydrae, naamlik tuinboukunde, vryetyddienslewering en bestuur. ${ }^{21}$ Met inagneming van die belang van bogenoemde terreine, word die bydrae wat 'n plantkundige kan lewer tot die uitbou van hierdie beroep in hierdie artikel bespreek. Die rol van die plantkundige in plaaslike bestuur moet hier nie gesien word as kompeterend met dié van die tuinboukundige nie. Die funksies wat beamptes in hierdie twee betrekkings onderskeidelik vervul sal ondersteunend tot mekaar wees. Hierdie is dus nie 'n pleidooi om weg te doen met tuinboukundiges nie, maar eerder om die besondere vaardighede waaroor 'n gegradueerde plantkundige beskik te beklemtoon.

\subsection{Die bewaring van ekosisteme - 'n lewensnood- saaklike opvoedingstaak}

Die wisselwerking wat tussen die mens en sy omgewing bestaan, kan nie ontken word nie en 'n toenemende bevolking lei noodwendig tot meer druk op die mens se onmiddellike omgewing. Tot onlangs het die bevolking van Suid-Afrika teen 'n tempo van 60000 persone per maand toegeneem. ${ }^{22}$ Daar word ook in die vooruitsig gestel dat die totale bevolking van die RSA teen die einde van die eeu teen 'n tempo van 1210000 persone per jaar sal aanwas. ${ }^{23}$ In 'n verslag van die Wetenskapkomitee van die Presidentsraad oor demografiese tendense in Suid-Afrika word 'n totale bevolkingsgetal van 74 miljoen vir die jaar 2050 geprojekteer. ${ }^{24}$ 'n Voorwaarde vir hierdie projeksie is dat 'n gemiddelde gesinsgrootte van 2,5 tussen die jare 2000 en 2005 bereik moet word. Gesien teen die agtergrond hiervan sal daar in die toekoms steeds groter druk op die RSA se natuurlike hulpbronne uitgeoefen word.

'n Ekologiese krisis wat nie alleen die lewenstandaard nie, maar ook die voortbestaan van die mens bedreig, staar ons dus in die gesig. Hierdie krisis vind hoofsaaklik sy oorsprong in die wanbestuur van ekosisteme. ${ }^{25.26}$ Die ekosisteem word hier gedefinieer as 'n funksionele eenheid in ekologie en sluit alle aspekte van beide die biotiese gemeenskap en abiotiese omgewing in. Die natuurlike plantegroei van ons land, as onderafdeling van enige ekosisteem, sal dan ook noodwendig aan die druk veroorsaak deur 'n onrusbarende bevolkingsgroei, onderwerp word. So, byvoorbeeld, word daar beraam dat, slegs ten opsigte van vuurmaakhout, ongeveer 10000000 ton per jaar in die ontwikkelende lande benodig word. ${ }^{27}$ Die gevaar van oorbenutting en wanbestuur van ons inheemse plantegroei is dus 'n werklikheid wat nie ontken kan word nie. Gesien in die lig hiervan word plaaslike owerhede met 'n gulde geleentheid gekonfronteer om die natuurlike plantegroei wat onder hul beheer staan nie alleen te bewaar nic, maar ook oordeelkundig te benut.

\section{DIE BYDRAE VAN 'N PLANTKUNDIGE TOT PARKE EN ONTSPANNING}

Die terreine waarop die plantkundige binne 'n plaaslike owerheid 'n groot bydrae kan lewer, kan in twee omvattende kategorieë gegroepeer word, naamlik navorsing en opvoedkunde. Hoewel hierdie twee rigtings onderling aan mekaar verwant is, word elkeen afsonderlik bespreek.

\subsection{Navorsing}

Binne navorsing, in die breë gesien, kan daar ook etlike fasette onderskei word wat afsonderlike vermelding regverdig. In die besonder kan 'n gekoördineerde, bewaringsgerigte navorsingsprogram wat deur Afdelings van Parke en Ontspanning uitgevoer word, bydra tot die identifisering van gebiede waar die plantegroei ontoereikend bewaar word. Sodanige studies sal toon watter plantsoorte in die betrokke streek skaars of bedreigd is. Die uitvoer van projekte gerig op die kweek, vermeerdering en verspreiding van hierdie plante sal noodwendig inligting beskikbaar stel wat vir beide tuinbou- en plantkundiges van nut sal wees. Die belang van navorsing, as wetenskaplike metode, kan nooit oorskat word nie en kan tot 'n groot mate daartoe bydra om Parke en Ontspanning se aanspraak op professionele status te versterk. ${ }^{21}$

\subsubsection{Natuurbewaring}

'n Onlangsc ondersoek het aan die lig gebring dat 1915 of nagenoeg $8 \%$ van die vaatplante (varings, naaksadiges en blomplante) van suidelike Afrika óf uitgesterf het óf op een of ander manier bedreig word. ${ }^{9}$ Dieselfde studie het aangetoon dat, ten minste in die suidwestelike Kaap, die helfte van die faktore wat die afname in plantegetalle veroorsaak direk na menslike bedrywighede herlei kan word. Hierdie bedrywighede sluit landboukundige, industriële en stedelike ontwikkeling sowel as onoordeelkundige plantversamelings in. Die verslag wat Hall et al. ${ }^{9}$ gepubliseer het, is nie volledig nie en verteenwoordig dan ook slegs 'n nuttige basis waarvandaan die opvolgnavorsing uitgevoer kan word.

Slegs 'n kennis van watter plante bedreig word, is onvoldoende. Dinamiese en daadwerklike optrede om die verdere agteruitgang van die natuurlike plantegroei te bekamp is nodig. Die ideaal sou wees dat minder as $8 \%$ van ons plantegroei op toekomstige gevaarlyste moet verskyn. Hall $^{28}$ het egter getoon dat hierdie syfer tans tot ongeveer $10 \%$ (2 373 bedreigde vaatplantspesies) toegeneem het. Die welslae wat deur Kirstenbosch Nasionale Botaniese Tuin behaal is met die kweek van byvoorbeeld Lachenalia mathewsii Barker, wat tot onlangs as uitgestorwe beskou is, is ' $n$ goeie voorbeeld van die bydrae wat op hierdie terrein gelewer kan word. ${ }^{29}$ 'n Klein groepie van laasgenoemde bolplantsoort is gedurende 1982 te Vredenburg ontdek. Plante wat van saad gekweek is, sal hopelik in die toekoms in hul natuurlike habitat hervestig kan word. Waarskynlik die grootste krisis waarmee natuurbewaringstrategieë tans gekonfronteer word, is die gebrekkige inligting aangaande die bewaringstatus van ons flora. 
Simon ${ }^{30}$ merk tereg op dat konkretc inligting aangaande die vernietiging van natuurlike habitats, met die gepaardgaande uitsterwing van plant- en diersoorte, hopeloos onvolledig is. Juis op hierdie terrein kan 'n plantkundige vir elke plaaslike owerheid 'n waardevolle bydrae lewer. Die versameling en disseminering van inligting oor die bewaring van bedreigde plantsoorte in die gebiede wat onder die jurisdiksie van plaaslike besture ressorteer, kan uiteindelik 'n nasionale bewuswording tot gevolg hê en tot 'n eenparige bewaringsaksie lei. ${ }^{3 !}$

'n Goeie voorbeeld van wat op plaaslike bestuursvlak vermag kan word ten opsigte van wandelpadbeplanning en natuurbewaring, word ons gebied deur die Stadsraad van Roodepoort. 'n Twaalf hektaar gedeelte van Ruimsig, 'n nuwe spogwoonbuurt, is onlangs as reservaat geproklameer om sodoende die laaste broeiplek bekend vir die skoenlapper Aloeides dentatis (Engels: Roodepoort copper) te beskerm. Beide die plantsoort Hermannia depressa N.E. $\mathrm{Br}$. en die miersoort Acantholepsis capensis, wat noodsaaklik is vir die suksesvolle voortplanting en dus oorlewing van bovermelde skoenlapper, kom in hierdie gebied voor. ${ }^{32,33}$

'n Verdere studieveld wat tot dusver baie min aandag geniet het, is die oorbenutting van medisinale plante en inheemse plantmateriaal wat vir die produksie en verkope van handwerk gebruik word. In Natal/KwaZulu alleen word nagenoeg 400 inheemse plantspesies medisinaal benut en sedert 1960 beleef die kommersiële bemarking van hierdie plante 'n ongekende opbloei. ${ }^{34.35}$ Voortgesette onbeheerde en grootskaalse benutting van hierdie spesies kan reeds kwesbare planthulpbronne onherstelbare skade berokken. Hierdie probleem kan gedeeltelik opgelos word deur die spesies wat oorbenut word op groot skaal te kweek. Die lewensvatbaarheid van so 'n projek word duidelik getoon deur die sukses wat die Departement van Parke, Ontspanning en Strande van die Durbanse Stadsraad reeds daarmee behaal het. ${ }^{35,36,37}$

\subsubsection{Die kweek van skaars, bedreigde en nuttige plantsoorte}

Eloff ${ }^{38.39}$ identifiseer twee langtermyn doelstellings vir die benutting van inheemse plantsoorte deur die Nasionale Botaniese Tuine, te wete die identifisering van inheemse plantsoorte met tuinboukundige, ekonomiese of medisinale waarde en die beskikbaarstelling van saad, plante en blomme daarvan direk of indirek aan die publiek.

Hierdie doelstellings verskaf aan plaaslike besture 'n hoogs bruikbare strategie vir die inrig en bestuur van hul kwekerye. Die noue onderlinge verwantskap wat tussen natuurbewaring en kwekerypraktyk gesmee kan word, tree ook sterk na vore. Indien skaars, inheemse plantsoorte op 'n beheerde en georganiseerde wyse aan die publiek beskikbaar gestel kan word, sal dit dus vir 'n plaaslike owerheid moontlik wees om die onoordeelkundige versameling van veldplante grootliks te help bekamp.

'n Munisipale kwekery hoef egter nie met kommersiële kwekerye om die kopersmark mee te ding nie. Deur korrekte opvoeding van die publiek kan die plaaslike owerhede daartoe bydra om 'n algemene aanvraag vir inheemse plantsoorte as tuinplante te skep. Kommersiële kwekerye sal dus tot 'n al groter mate verplig wees om aan hierdie vraag te voldoen. Deur middel van noue skakeling tussen kwekerye en die kwekerye van munisipale owerhede kan laasgenoemde met vrug in 'n voorsienende en raadgewende hoedanigheid optree.

Wanneer 'n plaaslike owerheid hierdie terrein betree sal dit noodwendig lei tot navorsing aangaande die kweek van plante en dan veral inheemse plantsoorte wat geskik is vir aanplanting in hul betrokke streek. Sodoende kan 'n databank opgebou word waarin, byvoorbeeld, kiemingsvereistes, plantvermeerderingstegnieke en aanplantingsgeskiktheid duidelik geïllustreer word.

\subsubsection{Die aanplant van straatbome}

Pad- en parkverfraaiing as een van die dienste wat Afdelings van Parke en Ontspanning aan 'n dorp of stad verskaf, geniet feitlik deur die land die nodige aandag. So, byvoorbeeld, eksperimenteer die Parkeafdeling van die Stadsraad van Kaapstad reeds vir etlike jare met inheemse bome as moontlike padverfraaiers. ${ }^{40}$ Ten spyte van probleme soos geografiese ligging, wisselende heersende winde en geologiese oorwegings het plaaslike owerhede landwyd reeds besondere sukses met die gebruik van inheemse bome as straatbome behaal. Voorlopige lyste van geskikte bome is dan ook reeds gepubliseer. ${ }^{41,42}$

Nadat op geskikte bome vir straataanplanting besluit is, moet die plaaslike owerheid steeds daartoe in staat wees om 'n omgewing te skep waarin die bome kan groei en wasdom bereik. Sekerlik een van die belangrikste faktore wat normale groei kan strem is 'n gebrekkige watertoevoer. In Denemarke is bevind dat 'n silwerberkeboom (Betula pendula Roth.) wat $12 \mathrm{~m}$ hoog en 28 jaar oud is tot 140 liter water per dag kan transpireer. ${ }^{43}$ Hoewel dit moeilik sal wees om hierdie waarde na Suid-Afrikaanse toestande te ekstrapoleer, gee dit tog ' $n$ aanduiding van die hoeveelheid water wat een boom per dag benodig om normale groei te kan voortsit. Dit is egter noemenswaardig dat Van Rooyen et $a l .^{44}$ bevind het dat 'n olienhoutboom (Olea europaea L. subsp. africana (Mill.) P.S.) wat naby Pretoria groei teen 'n baie hoër tempo transpireer as die naverwante olyfboom (Olea europaea L. subsp. europaea) wat in Europa groei.

Etlike praktyke wat tans in gebruik is om reënwater so spoedig moontlik af te voer, hetsy die onoordeelkundige inrig van stormwaterslote of die bedekking van die grondoppervlak tot teenaan boomstamme, sal dus in heroorweging geneem moet word. By die beplanning van 'n lewensvatbare boomaanplantingsprogram kan 'n plantkundige 'n deurslaggewende bydrae lewer om sukses te verseker. Dit sluit voorafgaande navorsing rakende die mees geskikte bome in, asook nasorg wat sal verseker dat die gekose bome 'n aanwins vir die omgewing sal wees.

\subsection{Opvoedkunde}

Hierdie onderafdeling van die rol wat 'n plantkundige op plaaslike bestuursvlak kan speel, geniet landwyd waarskynlik die minste aandag. Tog beskik munisipaliteite oor 'n unieke geleentheid om die publiek by plantkundigopvoedkundige programme te betrek. Die opvoedingstaak van die Nasionale Botaniese Tuine geskied hoofsaaklik binne twee sfere, naamlik formele en nie-formele onderrig. ${ }^{45}$ In beide hierdie rigtings kan plaaslike besture ' $n$ belangrike bydrae lewer tot algemene plantkundige opvoeding. ${ }^{46}$ Elke munisipaliteit beskik immers oor 'n 
park of tuin wat aangepas of ontwikkel kan word om te dien as opvoedingsentrum.

\subsubsection{Formele onderrig}

Die formele opvoedingstaak by die Nasionale Botaniese Tuin, Kirstenbosch, word deur twee biologieonderwysers wat deur die Kaapse Provinsiale Administrasie aangestel en besoldig word, gehanteer. Onder hul leiding het nagenoeg 8000 skoolkinders die Tuin gedurende 1984 besoek. Die ouderdomme van hierdie kinders wissel van 10 tot 12 jaar. $^{45}$ Die Laeveldse Botaniese Tuin te Nelspruit is deur nagenoeg 3500 skoolkinders besoek. Tydens hierdie besoeke is die skoliere en hul onderwysers deur óf die kurator van die Tuin óf een van sy senior personeellede vergesel en is die opvoedingstaak hier deur die plantkundiges self behartig. Dit verteenwoordig dan ook een van die belangrikste terreine waarop 'n plantkundige op 'n georganiseerde wyse die jeug aan die ryke Suid-Afrikaanse flora bekend kan stel. Noue samewerking tussen plaaslike onderwysowerhede en die Afdeling Parke en Ontspanning kan 'n plantkundige daartoe in staat stel om kurrikulumgerigte onderrig aan groepe skoliere en, indirek dus, ook die onderwysers te verskaf. ${ }^{46,47}$ Die belang van ' $n$ jeug wat van sy omgewing bewus gemaak word, spreek vanself.

\subsubsection{Nie-formele onderrig}

Eloff $^{45}$ aanvaar die volgende definisie vir nie-formele onderrig: "geordende en beplande, maar hoogsaanpasbare onderrig, byvoorbeeld indiensopleiding." Die definisie sluit uiteenlopende terreine in waarop 'n plantkundige 'n bydrae kan lewer. So byvoorbeeld kan die verskaffing van plantkundige onderrig aan vrywillige tuingidse plaaslike owerhede daartoe in staat stel om 'n groter mate van skakeling met die publiek te bewerkstellig. Aangesien daar tans by munisipaliteite 'n neiging bestaan om aan tuiboukundiges indiensopleiding beskikbaar te stel is die infrastruktuur vir hierdie aktiwiteit in sekere gevalle reeds geskep. ${ }^{48}$ 'n Soortgelyke diens wat deur vrywilligers verskaf word, kan 'n besoek aan enige plaaslike tuin of park 'n verrykende uitstappie maak.

Verdere moontlikhede sluit die aanbieding van jaarlikse kompetisies in wat oor inheemse plante, bewaring of aanverwante onderwerpe handel. Soortgelyke kompetisies deur Kirstenbosch uitgeskryf lok jaarliks etlike duisende inskrywings van skoliere van oor die hele Republiek. ${ }^{45}$

'n Permanente uitstallingslokaal, soortgelyk aan die een wat in die Setlaarspark te Port Elizabeth opgerig is, kan as 'n doeltreffende vertoonvenster vir ons inheemse plantegroei dien. Besoekers aan 'n park of tuin kan deur middel hiervan met vrug aan die blommeprag van ons land bekend gestel word.

Die geskrewe woord is van die belangrikste nie-formele onderrigmediums. Deur middel van 'n gereelde plantkunderubriek in 'n plaaslike koerant kan die publiek gereeld op hoogte gehou word van die aktiwiteite van tuine en parke onder die bestuur van die betrokke plaaslike owerheid. Die aankondiging van begeleide toere deur die tuine, die bekendstelling van bewaringswaardige gebiede en opvoedkundige programme wat aangebied word sowel as nuttige wenke rakende die aanplant en versorging van inheemse plante is maar enkele aspekte wat in so 'n rubriek vermeld kan word. Deur die publiek se belangstelling in die aktiwiteite van tuine en parke te prikkel kan groter betrokkenheid by die werksaamhede van Afdelings van Parke en Ontspanning bewerkstellig word.

\subsubsection{Park- en tuinuitleg}

Die estetiese rol van parke en tuine wat onder die beheer van munisipaliteite of stadsrade staan, kan moeilik na waarde geskat word. Plante in die algemeen het nog altyd 'n groot rol by die mens se genieting van buitemuurse aktiwiteite gespeel. Juis as gevolg daarvan het dit dikwels gebeur dat groot klem gelê word op die aanplant van mooi en skouspelagtige plantsoorte om deurlopend 'n treffende vertoning van blomme te verskaf. Veral vir die stadsmens, wat dikwels aan werkspanning onderworpe is, verteenwoordig enige buitemuurse uitstappie 'n ontvlugting van die daaglikse gejaag.

Om in hierdie behoefte te voorsien is dit nie nodig om net van aangeplante tuine gebruik te maak nie. Etlike Stadsrade het reeds begin om gedeeltes van die natuurlike omgewing onder hul beheer, vir hierdie doel te ontwikkel. So byvoorbeeld het die Stadsraad van Klerksdorp onlangs gedeeltes van die sogenaamde Oudorp-wandelroete bekend gestel. Die betrokke wandelpad maak deel uit van 'n reeks wandelroetes wat deur die Stadsraad in die vooruitsig gestel word. Die primêre doel van die projek is om die bewaringswaardige gebiede van Klerksdorp nie alleen te bewaar nie, maar ook tot hul volle potensiaal vir ontspanningsdoeleindes te benut. Die noue samewerking wat tussen die Stadsraad van Klerksdorp en die plaaslike tak van die Stigting Simon van der Stel met die uitvoer van hierdie projek bewerkstellig is, is ' $n$ uitstekende voorbeeld van die waardevolle skakeling wat tussen bewaringsbewuste organisasies kan bestaan.

Aangeplante tuine en parke kan aangepas word om as plantkundige inligtingsentrums te dien. Veral met die oog op die implementering van opvoedkundige programme kan 'n tuin met 'n wetenskaplike element hoogs bruikbaar wees. Die kweek van plante afkomstig uit verskillende ekologiese streke sowel as die saamgroepering van naverwante plantsoorte is maar twee voorbeelde van projekte wat in 'n park of tuin aangepak kan word.

Die uitlê van opeenvolgende formele beddings waarin plantsoorte filogeneties gerangskik word, is 'n verdere projek wat met vrug in opvoedkundige programme gebruik kan word. Dit kom neer op die verskaffing van 'n beknopte samevatting van die onderlinge verwantskappe tussen plantgroepe; dus, die planteryk in 'n neutedop. Gedeeltes van die botaniese tuine van die Institut für Allgemeine Botanik und Botanischer Garten, Hamburg, en die Universiteit van Freiburg beide in Wes-Duitsland wat so uitgelê is, word reeds vir 'n geruime tyd as 'n voortreflike onderrigmedium gebruik.

Die ideaal sou wees om 'n tuin- en/of veldgids beskikbaar te stel met behulp waarvan skoliere en die publiek sonder begeleiding, inligting uit die gebied kan bekom. Die aanbring van naambordjies wat die wetenskaplike naam, volksnaam, streek van herkoms en, indien toepaslik, ook die boomnommer verskaf, sal hiervoor onontbeerlik wees. 


\section{BESPREKING}

Aan die individue wat binne Parke en Ontspanning werksaam is, word tans groter eise gestel as bloot die lewering van tuinboukundige dienste en die aanbied van ontspanningsprogramme. Beamptes wat tans betrekkings in hierdie sfeer van plaaslike bestuur beklee, behoort oor die vermoë te beskik om met mense sowel as plante te werk. Uit hierdie studie is dit duidelik dat daar tans op die terrein van die plantkunde opvallende moontlikhede bestaan vir gemeenskapsgeörienteerde dienslewering. Dit blyk ook duidelik uit die feit dat plantgemeenskapskaarte as uitvloeisel van ekologiese opnames reeds met groot sukses in stedelike beplanning in Europa toegepas word. ${ }^{49.50}$

Die invoer van wetenskaplik gefundeerde kundigheid kan enige beroep slegs tot voordeel strek. Die indiensneming van gegradueerde plantkundiges kan derhalwe ook grootliks bydra tot beroepsvestiging en mannekragopgradering waaraan daar tans ' $n$ baie groot behoefte is. ${ }^{21}$

\subsection{Toekomsstrategieë}

Plaaslike besture in die algemeen beskik oor die vermoë om 'n groter waardering vir inheemse plante onder die publiek te vestig sowel as om bedreigde plantsoorte te vermeerder en te versprei. Om hierdie doelstellings, wat beide opvoeding en navorsing impliseer, te kan realiseer sal aandag aan die volgende sake geskenk moet word:

1. Die opstelling van 'n omvattende strategie gerig op die bewaring en oordeelkundige benutting van natuurlike hulpbronne.

2. Vestiging en bestuur van 'n kwekery waar die nut van inheemse plantsoorte as tuin- en straatplante ondersoek kan word.

3. Kweek en verspreiding van skaars of bedreigde plantsoorte wat in die betrokke streek voorkom.

4. Inwin van inligting oor die bewaringstatus van die natuurlike omgewing.

5. Noue samewerking tussen plant- en tuinboukundiges om 'n lewensvatbare straatboomaanplantingsprogram te ontwerp.

6. Betrokkenheid by sillabusgerigte plantkundige onderrig vir skoliere.

7. Skepping van 'n tuin of park met 'n wetenskaplike strekking.

8. Gereelde publisering van plantkundige inligting en die bekendstelling van aanverwante aktiwiteite.

\subsection{Aanbevelings}

Om in die veranderende behoeftes van groeiende stedelike bevolkings te kan voorsien, is dit belangrik om ook aandag te skenk aan beroepsontwikkeling op plaaslike bestuursvlak en in hierdie geval dan die omvang van dienste wat plantkundiges kan lewer. Hoewel baie van die aspekte wat in hierdie stuk vermeld word reeds die aandag van verskeie plaaslike owerhede geniet, bestaan daar landwyd ruimte vir die aanstelling van plantkundiges op plaaslike bestuursvlak. Hulle beskik oor die akademiese agtergrond en kundigheid om 'n onmisbare bydrae te lewer tot die werksaamhede van Afdelings van Parke en Ontspanning. Gegradueerdes met plantkunde as een hoofvak, bied 'n oplossing, veral nog as tuinboukunde in die kurrikulum opgeneem kan word.

\section{DANKBETUIGINGS}

Die skrywer wil graag sy dank uitspreek teenoor professor G.J.L. Scholtz vir waardevolle samesprekings.

\section{VERWYSINGS}

1. Rycroft, H.B. \& Ryan, R. (1980). Kirstenbosch (Howard Timmins, Cape Town)

2. Gunn, M. \& Codd, L.E. (1981). Botanical exploration of Southern Africa (Balkema, Cape Town).

3. Takhtajan, A. (1961). Flowering plants: Origin and dispersal (Oliver \& Boyd, Edinburgh).

4. Jarman, M. (1982). A look at the littlest floral kingdom, Scientiae, July - September: 9-19.

5. Delpierre, G.R. \& Du Plessis, N.M. (1973). The winter-groning gladioli of South Africa (Tafelberg. Cape Town).

6. Dyer, R.A. (1976). The genera of southern African flowering plants, Volume 1. (Departement van Landbou-tegniese Dienste, Pretoria).

7. Goldblatt, P. (1978). An analysis of the flora of southern Africa: its characteristics, relationships and origins, Ann. Missouri Bot. Gard., $65,369-436$

8. Rutherford, M.C. \& Westfall, R.H. (1986). The biomes of southern Africa - an objective categorization, Mem. Bot. Opn. S. Afr. , 54, 1-98.

9. Hall, A.V., De Winter, M., De Winter, B. \& Van Oosterhout, S.A.M (1980). Threatened plants of southern Africa. South African National Scientific Programmes Report No. 45, (CSIR, Pretoria).

10. Gibbs Russell, G.E. (1987). Preliminary floristic analysis of the major biomes in southern Africa, Bothalia, 17, 213-227.

11. Jeppe, B. (1975). Natal wild flowers (Purnell, Cape Town).

12. Van Wyk, B-E.. Van Wyk, C.M. \& Novellie, P.A. (1988). Flora of the Zuurberg National Park, Part 2, An annotated checklist of ferns and seed plants, Bothalia, 18, 221-232.

13. Gibbs Russell, G.E., Welman, W.G., Germishuizen, G., Retief, E. Pienaar, B.J., Reid, C., Fish, L., Van Rooy, J., Van Wyk, C.M., Kalake, E. \& Staff. (1988) New taxa, new records and name changes for southern African plants, Bothalia, 18, 293-304.

14. Botha, D.J. (1981). Die ekonomiese potensiaal van sommige van ons Suid-Afrikaanse veldplante. Intreerede, Potchefstroosme Universiteit vir Christelike Hoër Onderwys, Reeks H nr. 83, P.U. vir C.H.O.

15. Bayer, M.B. (1984). The Cape flora and the Karoo - a winter rainfall biome versus a fynbos biome, Veld \& Flora, 70, 17-19.

16. Hilton-Taylor, C. \& Moll, E. (1986). The Karoo - a neglected biome, Veld \& Flora, 72, 33-36.

17. Acocks, J.P.H. (1988). Veld types of South Africa, Mem. Bot. Opn. S. Afr., 57, 1-146.

18. Penzhorn, B.L. \& Olivier, M.C. (1974). A systematic check list of flowering plants collected in the Addo Elephant National Park, Koedoe, 17, 12!-136.

19. Olivier, M.C. (1981). An annotated systematic check list of the Spermatophyta of the Springs Reserve, Uitenhage, J. S. Afr. Bot., 47, 813-828.

20. Olivier, M.C. (1986). Valley Bushveld - an endangered veld type, Veld \& Flora, 72, 49-50.

21. Scholtz, G.J.L. (1986). Professionele status van Parke en Rekreasie Studiestuk 11, (Instituut vir Vryetydstudies, P.U. vir C.H.O.). Vryetydstudies. PU vir $\mathrm{CHO}$

22. Hall, A.V. (1978). Endangered species in a rising tide of human population growth, Trans. Roy. Soc. S. Afr. 43, 37-49.

23. Sadie, J.L. (1978). The demographic forces in South Africa, Trans. Rov: Soc, $S$. Afr., 43, 11-23

24. Verslag van die Wetenskapskomitee van die Presidentsraad. (1983) Demografiese tendense in Suid-Afrika (Staatsdrukker, Kaapstad).

25. Hale, M. (1987). Urban ecology: a problem of definition?, J. Biol. Educ:, 21, 14-16.

26. Taljaard, E.P.S. (1989). The effect of recreational use on natural areas and the rehabilitation of affected areas, Tydskr. Inst. Parke en Ontspanningsadministrasie (S.A.), 42(1), 12-16.

27. Van Vuuren, D.R.J. \& Bredenkamp, G.J. (1980). The role of botany in developing communities in southern Africa. In Where theory meet practice: the Faculty of Science in service of the community. Els, W.J. ed. (Universiteit van die Noorde, Pietersburg) pp. 119-132.

28. Hall, A.V. (1989). The conservation of threatened plant species, Tydskr. Inst. Parke en Ontspanningsadministrasie (S. A.), 42(2), 38-42.

29. Duncan, G. (1986). The re-discovery of Lachenalia mathewsii W.F Barker, Veld \& Flora, 72, 40-41.

30. Simon, J.L. (1986). Disappearing species, deforestation and data, New Scientist, 10 (1508), 60-63.

31. Low, B. (1987). Non-government conservation: Clarifying future roles in urbanizing greater Cape Town, Veld \& Flora, 73, 68-71.

32. Anoniem. (1986). Fascinating wildlife relationship preserved. Our Living World, 6, 6. 
33. Bosman, D. (1988). Die praktiese toepassing van die wandel/voetslaanpadbegrip in stedelike omgewings met spesiale vewysing na die stad Roodepoort. Tydskr. Inst. Parke en Ontspanningsadministrasie (S. A.), 41(4), 14-19.

34. Cunningham, A.B. (1987). Commercial craftwork: Balancing out human needs and resources, S. Afr. Tydskr. Plantk., 53, 259-266.

35. Cunningham, A.B. (1988). Over-exploitation of medicinal plants in Natal/KwaZulu. Root causes, Veld \& Flora, 74, 85-87.

36. Nichols, G. (1988). Conservation imperatives in a first and third world city. Proceedings of the 12th plenary AETFAT congress, 176. (Institut für Allgemeine Botanik und Botanischer Garten, Hamburg), (Uittreksel).

37. Nichols, G. (1989). Growing medicinal plants - the Durban experience. Tydskr. Inst. Parke en Ontspanningsadministrasie (S. A.), 42(1), 9-11.

38. Eloff, J. N. (1984). Kirstenbosch, quo vadis'? Spesiale Verslag, Veld \& Flora, 70, i-iv.

39. Eloff, J.N. (1987). Plantbenutting: 'n Kernaktiwiteit van die Nasionale Botaniese Tuine, S.A. Tydskrif vir Natuurwetenskap en Tegnologie, 6, 123-129.

40. Anoniem, (1986). Gebruik van inheemse bome vir straatboomaanplanting, Veld \& Flora, 72, 82-83.

41. Donald, D.G.M. (1989). The use of indigenous trees in the municipal areas of South Africa, Tydskr. Inst. Parke en Ontspanningsadministrasie (S.A.), 42(2), 12-17.
42. Gibbs, P. (1989). The utilisation of indigenous flora, Tydskr. Inst. Parke en Ontspanningsadministrasie (S.A. ). 42(2), 4-12.

43. Larcher, W. (1983). Phwsiological plant ecology, 2nd ed., (SpringerVerlag. Heidelberg).

44. Van Rooyen, N., Van Rooyen, M.W., Theron, G.K. \& Grobbelaar N. (1986). The vegetation of the Roodeplaat Dam Nature Reserve VI. Photosynthesis and transpiration in woody plants with reference to an evergreen tree Olea europaed subsp. africana, S. Afr. Tidskr. Plantk., 52, 301-308.

45. Eloff, J.N. (1985). Conservation through education - a prime function of the National Botanic Gardens, Veld \& Flora, 7I, i-vii.

46. Marshall, E. (1988). Die belangrikheid van natuurgebiede, Tydskr. Inst. Parke en Ontspanningsadministrasie, (S.A.), 41(1), 14-18.

47. De Graaff. D. (1988). Principles and techniques for the management and conservation of fauna and flora in National Parks and Game Reserves, Tydskr. Inst. Parke en Ontspanningsadministrasie (S.A.) 4I(3), 25-3I.

48. Butf, A.E. (1986), Practical training: student horticulturist, ParkeAdministrasie, 39, 28-40.

49. Olaczek, R. (1982). Application of phytosociological maps to urban planning, with reference to two small towns in Central Poland. In Urban ecology, Barnkamm, R., Lee, J.A. \& Seaward, M.R.D. eds. (Blackwell Scientific, London).

50. Middleton, T. (1988). Town planning - its role and relationship to public open space, Tydskr. Inst. Parke en Ontspanningsadministrasie (S. A. ), 41(1), 10-13. 